\title{
Assessing the Role of Individual Variables in Determining the Research and Development Engineers' Creativity A Study in Electrical and Electronics Industry
}

\author{
Chengling Tan, Yali Hong \\ Graduate School of Business, Universiti Sains Malaysia, Penang, Malaysia \\ Email: tanchengling@usm.my \\ Received 2012
}

\begin{abstract}
This study examined the direct effect of individual variables (self-esteem, creative self-efficacy, intrinsic motivation and extrinsic motivation) on the Research and Development (R\&D) engineers' creativity. The data were analysed based on questionnaires returned by $130 \mathrm{R} \& \mathrm{D}$ engineers attached to fifteen Electrical and Electronic (E\&E) firms with R\&D department in Penang, Malaysia. The convenience sampling method was employed in getting the samples. The results posited that all individual variables were positively related to R\&D engineers' creativity. The results also reported that there is no significant difference in $R \& D$ engineers' creativity between contract employment type and permanent employment type. The theoretical and practical implications of the study as well as suggestion for future studies were also discussed.
\end{abstract}

Keywords: Creativity; R\&D Engineer; Individual Variables; E\&E Industry; Type of Employment

\section{Introduction}

The global economy is becoming increasingly competitive. Talent will be characterized as one of the important roles in supporting Malaysia to realize the objective of propelling the economy to a high income status. Therefore, the great attention must be given to human capital that lies at the core of innovation and a productive high income economy. In order to achieve Malaysia's aspirations, it is important to develop, attract and retain a first world talent base. However, the $10^{\text {th }}$ Malaysia Plan (10MP) recognizes that Malaysia is facing severe human capital deficiency problem. In conjunction with that, Talent Corporation (TC) is setup by Prime Minister of Malaysia, YAB Dato Seri Mohd Najib, in 2011 to attract, nurture and retain talent required for high income economy, which is in line with the Economic Transformation Program (ETP). One of the key activities from TC is to develop a collaborative initiative among industries and government agencies to address talent requirement and demand in Malaysia.

Among the industries, Electrical and Electronic (E\&E) industry is in the top of the list to kick start this collaboration effort because it is an important contributor to the national economy, accounting for RM37 billion in Gross National Income ( $6 \%$ of national GNI), 522,000 jobs and $41 \%$ of Malaysia's total export in 2009 (Performance Management and Delivery Unit (PEMANDU), 2012). In addition, TC has a fast track program involves apprenticeship with hands on experience working on actual R\&D projects at host companies, like Intel and Altera, while it supplemented with formal training at Penang Skills Development Centre (PSDC).

Despite all exciting stack of R\&D projects roaring to roll out, too much time has been wasted without a proper appreciation of developing skilled R\&D engineers. From the global comparison, Malaysia's Gross Expenditure for R\&D (GERD) of RM
3.6 billion was ranked $37^{\text {th }}$ from the National $R \& D$ survey (2008). On the other hand, GERD/GDP ratio of 0.64 was placed on $44^{\text {th }}$ in the world. In comparison to Asia Pacific countries like Taiwan, Singapore, China, India and Hong Kong which accounted for 2.52, 2.36, 1.33, 0.84 and 0.74 respectively, Malaysia has the lowest ranking. Big gap is observed between Malaysia and the neighborhood countries despite overall Malaysia's R\&D performance still shows gradual growth. There is always a room for improvement and more effort is required to accelerate the current situation.

The R\&D engineers' capabilities to create, disseminate, and apply knowledge are critical factors in determining the R\&D engineers' creativity. The R\&D engineers' creativity includes generating new (novel or adopted) ideas and solutions, developing new product and new method, and producing an applicable prototype or model for the use of the organization. This implies that E\&E industry highly demand for the creative R\&D engineers to produce and develop innovation as well as, to help this E\&E industry to face the complexity of economic context and to go over the competitors. Given the importance of R\&D engineers' creativity in enhancing the E\&E firms' growth and performance; examining the influencing factors in stimulating R\&D engineers' creativity in order to bring the E\&E firms towards global competition is warranted.

In general, organization has widely recognized the influencing factors such as individual, organizational and environmental variables that will enhance R\&D engineers' creativity. Therefore, this study aims to explore and focus on the influence of personality factors that might help to increase the R\&D engineers' creativity level. Positive personality factors, such as self esteem, creative self efficacy, intrinsic motivation and extrinsic motivation affects and fosters cognitive complexity, creativity and innovation (Ford, 1996; Isen, 1999; Woodman, Sawyer, and Griffin, 1993). Personality development which 
refers to skills development and motivational enhancement, have played a significant role in most of the organization nowadays. With the right skill set, it smoothen the interaction between clients, co-workers and superiors. Subsequently, it helps the employee to face any challenges with confidence and positive approach (Barron and Harrington, 1981).

\section{Literature Review}

\section{R\&D Engineers' Creativity}

Global society is facing challenges that require innovative and practical engineering solutions. Survival of a company is very much depended on the ability of its engineers to innovate and stimulate their creativity, particularly in R\&D. This is because the R\&D engineers play a vital role in generating fresh solutions to problems and creating new products, processes or services for their company to sustain in this competitive edge. Scholar has formulated explicit distinctions between two main types of creativity, which are special talent (Maslow, 1962) and self-actualizing (Sawyer, 2006). Special talent is ascribed to people whose contribution is recognized by society (Sawyer, 2006). There is a myth that creativity is limited to several individual who are naturally creative. Self actualizing, on the other hand, is referring to collaborative, improvised, and it is influenced by shared cultural knowledge and processes. Creativity is a skill that can be learned and applied. Learning to be creative is akin to learning a sport. It requires practice to develop the right muscles, and a supportive environment in which to flourish. In this study, R\&D engineers' creativity is termed as the process of forming novel idea to solve problems and to increase the efficiency (Amabile, 1983; Woodman, et al., 1993).

\section{Individual Variables}

Individual variables are conceptualized as personal resources available to an individual (Gist and Mitchell, 1992). In this study, four common individual variables which were widely examined, namely self esteem, creative self efficacy, intrinsic motivation and extrinsic motivation are determined as the predictors to R\&D engineers' creativity. Self-esteem is defined as an individual's judgment of one's own value (Bandura, 1994). Creative self efficacy refers to the belief that an individual has the ability to produce creative outcomes (Walker, Greene, and Mansell, 2006). Intrinsic motivation is regarded as encouragement or motivation originating from an individual to increase one's satisfaction and competency to complete the task (Walker, et al., 2006). Extrinsic motivation is termed as the encouragement or external reward that brings expected behaviors and performance (Maltzman, 1960).

\section{Individual Variables and R\&D Engineers' Creativity}

Isen (1999) concluded that positive personality/individual variables will foster cognitive complexity, creativity and innovation. Personality development, in terms of skill development and motivational enhancement, has a significant role in most of the organization nowadays. With the right skill set, it smoothen the interaction between clients, co-workers and superiors. Subsequently, it helps the employee to face any challenges with confidence and positive approach. A review of literature illustrates that individual variables comprise of four common dimensions (self esteem, creative self efficacy, intrinsic motiva- tion and extrinsic motivation) that influence on the creativity. Therefore, our main hypothesis is constructed as follows:

$\mathrm{H}_{1}$ : Individual variables (self esteem, creative self efficacy, intrinsic motivation and extrinsic motivation) are positively related to R\&D engineers' creativity.

Self-esteem is crucial and as a cornerstone of a positive attitude towards living. Self esteem elaborates the affective aspect of self evaluation (Cheng and Furnham, 2004; Lightsey, Burke, Ervin, Henderson and Yee, 2006). Having a healthy dose of self-esteem allows individual to focus more on the pleasure of being creative. Thus, the first sub-hypothesis is postulated as below:

$\mathrm{H}_{1.1}$ : Self esteem is positively related to $\mathrm{R} \& \mathrm{D}$ engineers' creativity.

Creative self efficacy originated from the concept of self efficacy, which describes an individual belief on successfully performing in a particular setting (Bandura, 1994). In short, the employees tend to perceive opportunities to apply their creative potential in the form of creative actions. Hence, the second sub-hypothesis is presented as below:

$\mathrm{H}_{1.2}$ : Creative self efficacy is positively related to $\mathrm{R} \& \mathrm{D}$ engineers' creativity.

Intrinsic motivation views creativity as self-motivated psychological behavior that is triggered by intrinsic spiritual rewards (Deci and Ryan, 1985; Amabile, 1997; Hennessey and Amabile, 1998). The main component of intrinsic motivation is individual's level of enthusiasm for the activity as it affects one's decision to initiate and sustain creative effort over time (Amabile, 1988). Therefore, the third sub-hypothesis is conjectured as below:

$\mathrm{H}_{1.3}$ : Intrinsic motivation is positively related to $\mathrm{R} \& \mathrm{D}$ engineers' creativity.

Extrinsic motivation emphasizes on encouragement or external reward outside the self (Walker, et al., 2006). In line with Deci and Ryan (1985), the relationship between extrinsic and outcomes highly depends on the types of extrinsic motivation involved. Especially in formalized tasks, extrinsic rewards are seemed to be necessary to motivate employee creativity (Amabile, Hennessey, and Grossman, 1986). Thus, the fourth sub-hypothesis is formulated as below:

$\mathrm{H}_{1.4}$ : Extrinsic motivation is positively related to $\mathrm{R} \& \mathrm{D}$ engineers' creativity.

\section{Type of Employment as a Moderator}

In general, there are two types of employment, namely permanent and contract. Different types of employment will affect individuals' actions as the reward system included in the contract affects the efforts applied (Holmstrom and Milgrom, 1994) and knowledge applied (Conner and Prahald, 1996). The relationship between employee and organization is materially different for contract and permanent employee. The perceived obligation of loyalty in return of job security (contract and permanent) forms a relational psychological contract between worker and organization that has a link between the individual's commitments to the organization (Rosseau, 1990). Based on past studies, contract employees place less priority on job-related factor, such as creativity contribution and knowledge sharing (Wakefield, Curry, Mueller, and Price, 1987). On the other hand, permanent employees are more likely act collaboratively in the interests of the organization than individually in their own interest (Ohana and Meyer, 2010). As such, this 
study conceptualize that permanent employment positively moderate the relationship between individual variable and R\&D engineer's creativity. Conversely, contract employment negatively moderates the relationship between individual variables and R\&D engineer's creativity. Thus, the hypotheses for this study are formulated as follows:

$\mathrm{H}_{2}$ : Types of employment moderates the relationship between individual variables (self-esteem, creative self-efficacy, intrinsic motivation, extrinsic motivation) and the R\&D engineers' creativity.

$\mathrm{H}_{2.1}$ : Types of employment moderates the relationship between self-esteem and the R\&D engineers' creativity.

$\mathrm{H}_{2.2}$ : Types of employment moderates the relationship between creative self-efficacy and the R\&D engineers' creativity.

$\mathrm{H}_{2.3}$ : Types of employment moderates the relationship between intrinsic motivation and the R\&D engineers' creativity.

$\mathrm{H}_{2.4}$ : Types of employment moderates the relationship between extrinsic motivation and the R\&D engineers' creativity.

\section{Methodology}

The population of the present study will be the engineers employed in the R\&D organization in Penang, the main industrial hub as well as being home to the Free Trade Zone. Based on Invest Penang directory, there are 200 companies are involved in the electrical and electronics sector (E\&E). Of theses 200 companies, only 15 companies are with R\&D facilities. The questionnaires were sent to these 15 companies with intended of 15 respondents from each company. The unit of analysis is the engineer working in R\&D organization. The respondent will be sampled using convenient sampling method.

\section{Results}

\section{Profile of Respondents}

Among 130 respondents, 51 are male (39.2\%) and 79 are female (60.8\%). More than half of the respondents are married (51.5\%) while the rest are single (48.5\%). Majority of the respondents are Bachelor Degree holder (64.6\%). It is then followed by Master Degree holder (26.9\%), PhD holder (6.9\%) and Diploma holder (1.5\%). All the respondents are R\&D engineers $(100 \%)$ with permanent employment type (89.2\%) except fourteen (10.8\%) of them are under contract employment.

\section{Descriptive Statistics}

The mean score for $R \& D$ engineers' creativity $(M=3.74$, $\mathrm{SD}=0.70$ ) are perceived to be moderate by most of the respondents. And also, engineers in this study particularly gives weight to intrinsic motivation $(\mathrm{M}=3.93, \mathrm{SD}=0.60)$, followed by self esteem $(\mathrm{M}=3.75, \mathrm{SD}=1.05)$, extrinsic motivation $(\mathrm{M}$ $=3.61, \mathrm{SD}=0.67)$ and creative self-efficacy $(\mathrm{M}=3.57, \mathrm{SD}=$ $0.58)$.

\section{Multiple Regression Analysis}

Regression was conducted to test the hypotheses for this study. Table 1 shows the regression analysis the results for regression analysis of individual variables on R\&D engineers' creativity. The four individual variables are able to explain 58\% $\left(\mathrm{R}^{2}=0.58, \Delta \mathrm{F}\right.$-value $\left.=42.17, \mathrm{p}<0.01\right)$ of the observed variation on R\&D engineer's creativity. All four individual variables are significantly contributed to the prediction of $R \& D$ engi- neer's creativity. Self-esteem $(\beta=0.16, p<0.01)$, creative self-efficacy $(\beta=0.2, p<0.01)$, intrinsic motivation $(\beta=0.15$, $\mathrm{p}<0.05)$ and extrinsic motivation $(\beta=0.59, \mathrm{p}<0.01)$, are significant and have positive relationship with $R \& D$ engineer's creativity. Hence, the hypothesis $\mathrm{H}_{1}, \mathrm{H}_{1.1}, \mathrm{H}_{1.2}, \mathrm{H}_{1.3}$ and $\mathrm{H}_{1.4}$ are strongly supported.

Moderating effect analysis was also conducted to analyze the moderating role of type of employment. As shown in Table 2, it seems that the type of employment does not moderate all the relationship between individual variables (self-esteem, creative self-efficacy, intrinsic motivation and extrinsic motivation) and R\&D engineer's creativity. The interaction terms are insignificant, hence the $\mathrm{R}^{2}$ is maintained. In sum, hypotheses $\mathrm{H}_{2}, \mathrm{H}_{2.1}$, $\mathrm{H}_{2.2}, \mathrm{H}_{2.3}$ and $\mathrm{H}_{2.4}$ are not supported.

Table 1.

Mean Scores and Standard Deviations for the Study Variables.

\begin{tabular}{ccc}
\hline Variables & Mean (M) & Standard Deviation (SD) \\
\hline R\&D Engineer's Creativity & 3.74 & 0.70 \\
Individual Variables & & \\
Self-Esteem & 3.75 & 1.05 \\
Creative Self-Efficacy & 3.57 & 0.58 \\
Intrinsic Motivation & 3.93 & 0.60 \\
Extrinsic Motivation & 3.61 & 0.67 \\
\hline
\end{tabular}

Table 2.

Regression Results of the Relationship between individual Variables and R\&D Engineer's Creativity.

\begin{tabular}{|c|c|c|c|}
\hline \multirow{2}{*}{ Predictors } & Model 1 & Model 2 & Model 3 \\
\hline & Std. $\beta$ & Std. $\beta$ & Std. $\beta$ \\
\hline \multicolumn{4}{|c|}{ Step 1: Individual Related Variables } \\
\hline Self-Esteem (SE) & $0.16^{* *}$ & $0.14^{*}$ & 0.09 \\
\hline Creative Self-Efficacy (CSE) & $0.20 * *$ & $0.21^{* *}$ & 0.06 \\
\hline Intrinsic Motivation (IM) & $0.15 *$ & $0.16^{*}$ & -0.21 \\
\hline Extrinsic Motivation (EM) & $0.59 * *$ & $0.61^{* *}$ & 0.47 \\
\hline \multicolumn{4}{|l|}{ Step 2: Moderating Variables } \\
\hline Type of Emploment (EMP) & & $0.12 *$ & -0.63 \\
\hline \multicolumn{4}{|l|}{ Step 3: Interaction Term } \\
\hline SE x EMP & & & 0.08 \\
\hline CSE $x$ EMP & & & 0.22 \\
\hline IM x EMP & & & 0.52 \\
\hline EM x EMP & & & 0.17 \\
\hline $\mathrm{R}^{2}$ & 0.58 & 0.60 & 0.60 \\
\hline Adjusted $\mathrm{R}^{2}$ & 0.57 & 0.58 & 0.57 \\
\hline$\Delta \mathrm{R}^{2}$ & 0.58 & 0.01 & 0.00 \\
\hline F-value & $42.17^{* *}$ & $35.45^{* *}$ & $19.36^{* *}$ \\
\hline$\Delta \mathrm{F}$-value & $42.17 * *$ & $4.15^{*}$ & 0.30 \\
\hline
\end{tabular}

Note: ${ }^{*} \mathrm{p}<0.05,{ }^{* *} \mathrm{p}<0.01$ 


\section{Discussion and Conclusion}

All four individual variables were significant and positively related to R\&D engineer's creativity. Extrinsic motivation ( $\beta=$ $0.59, \mathrm{p}<0.01$ ), was found to be the strongest predictor. It was then followed by creative self-efficacy $(\beta=0.20, p<0.01)$, self esteem $(\beta=0.16, p<0.01)$, and intrinsic motivation $(\beta=0.15$, $p<0.05$ ). Extrinsically motivated engineer will perform to attain a desired grade or some other form of external rewards like money and recognition. Tangible incentives, tangible rewards and opportunities for promotion act as means to recognize engineer's effort in tangible ways. In conjunction with Abbey and Dickson (1983) study, the extrinsic motivation was consistently correlated with R\&D engineers' creativity. Next on the list was creative self-efficacy which highlighted that $R \& D$ engineers must possess the required technical skills, confidence and value orientation to be creative (Kirton, 1989). R\&D environment needs $R \& D$ engineers to be creative due to job complexity. It is because R\&D environment is in a setting which creativity is a priority and creative routine performances are closely linked. As such, the engineers conducting complex job would have greater creative self-efficacy. $R \& D$ engineers with high self-esteem believe that they will use the necessary capabilities to perform the task successfully. These engineers are likely to seek for challenges and adopt effective strategies to mediate the challenges (Bandura, 1994; Zeldin and Pajares, 2000). They would not be hurt easily by criticism of their creative ideas. It aligns with the past researches, self-esteem was positively related to creativity (Axtell, Holman, Unsworth, Wall, and Waterson, 2000; Gist, 1989). Intrinsic motivation is recognized as one of the core characteristics for engineer's creativity which relates to workplace creativity (Oldham and Cummings, 1996) as well as level of enthusiasm for the activity (Amabile, 1988). In short, with appropriate intrinsic motivational orientation for job involving creativity, the emergence of innovative ideas and express more creativity will be enhanced.

Employment type did not moderate the relationship between individual variables and R\&D engineer's creativity. One of the possible explanations would be related to the type of job that the engineer is working on. Additionally, one of the main characteristic of $R \& D$ job is that it is not a routine job. It is classified as job with high complexity (Hunter, Schmidt, and Judiesch, 1990) and analytic work (Gottfredson, 1986). Every $R \& D$ is different most of the time; otherwise organization would not have invested. Thus, the engineers, regardless in contract or permanent, who involved in the R\&D would feel challenging most of the time and continue to deliver quality and creative performance. The result of this study offers several suggestions to E\&E organizations in Malaysia. In particular, R\&D managers could use the results from this study to instill R\&D engineer's creativity by setting the significant personality criteria while recruiting the new $R \& D$ engineers.

\section{REFERENCES}

A. Abbey and J. Dickson, "R\&D work climate and innovation in semiconductors," Academy of Management Journal, vol. 26, 1983, pp. 362-368.

A. Bandura, "Self efficacy: The exercise of control," New York: Freeman, 1994.

A. L. Zeldin and F. Parajes, "Against the odds: Self efficacy believe of women in mathematical, scientific and technological careers," American Educational Research Journal, vol. 37, 2000, pp. 215-246.
A. H. Maslow, Toward a Psychology of Being. Princeton, NJ: Van Nostrand, 1962.

A. M. Isen, "Positive affect", In T. Dalgleish and M. Power (Eds.), The handbook of cognition and emotion. Wiley, 1999, pp. 521-539.

B. Holmstrom and P. Milgrom, "The firm as an incentive system," The American Economic Review, vol. 84, 1994, pp. 972-991.

B. A. Hennessey and T. M. Amabile, "Reward, intrinsic motivation, and creativity,” American Psychologist, vol. 53, 1998, pp. 674-675.

C. J. Axtell, D. J. Holman, K. L. Unsworth, T. D. Wall, and P. E. Waterson, "Shopfloor innovation: Facilitating the suggestion and implementation of ideas," Journal of Occupational and Organizational Psychology, vol. 73, 2000, pp. 265-285.

C. M. Ford, "A theory of individual creative action in multiple social domains,” The Academy of Management Review, vol. 21, 1996, pp. 1112-1142.

C. O. Walker, B. A. Greene, and R. A. Mansell "Identification with academics, intrinsic/extrinsic motivation, and self efficacy as predictors and cognitive engagement," Learning and Individual Differences, vol. 16, 2006, pp. 1-12.

D. M. Rosseau, "New hire perceptions of their own and their employer's obligations: A study of psychological contracts," Journal of Organizational Behaviour, vol. 11, 1990, pp. 389-400.

D. S. Wakefield, J. P. Curry, C. W. Mueller, and J. L. Price, "Differences in importance of work outcomes between full time and part time hospital employees,” Journal of Occupational Behavior, vol. 8, 1987, pp. 25-35.

E. L. Deci and R. M. Ryan, "Intrinsic motivation and self-determination in human behavior,” New York: Plenum, 1985.

E. S. Gottfredson, “Occupational aptitude patterns map: Development and implications for a theory of job aptitude requirements,” Journal of Vocational Behavior, vol. 29, 1986, pp. 254-291.

F. Barron and D. Harrington, "Creativity, intelligence and personality," In M. Rosenzweig and L. Porter (Eds.), Annual Review of Psychology, 1981, pp. 439-476.

G. Oldham and A. Cummings, "Employee creativity: Personal and contextual factors at work,” Academy of Management Journal, vol. 39, 1996, pp. 607-655.

H. Cheng and A. Furnham, "Perceived parental rearing style self-esteem, and self-criticism as predictors of of happiness,” Journal of Happiness Studies, vol. 5, 2004, pp. 1-21.

I. Maltzman, "On the training of originality,” Psychological Review, vol. 67, 1960, pp. 229-242.

J. E. Hunter, F. L., Schmidt, and M. K. Judiesch, "Individual differences in output variability as a function of job complexity,” Journal of Applied Psychology, vol. 75, 1990, pp. 28-42.

K. R. Conner and C. K. Prahald, "A resource-based theory of the firm: Knowledge versus oppoutunism,” Organization Science, vol. 7, 1996, pp. 477-501.

M. E. Gist, "The influence of training method on self-efficacy and idea generation among managers,” Personnel Psychology, vol. 42, 1989, pp. 787-805

M. Ohana, and M. Meyer, "Should I stay or should I go now? Investigating the intention to quit of the permanent staff in social enterprises,” European Management Journal, 2010, vol. 28, pp. 441-454.

M. J. Kirton, “A theory of cognitive style,” In M. J. Kirton (Eds). Adaptors and innovvators: Styles of creativity and problem solving. New York: Routledge, 1989, pp. 1-36.

O. R. Lightsey, M. Burke, A. Ervin, D. Henderson, and C. Yee, “Generalized self-efficacy, self-esteem and negative affect," Canadian Journal of Behavioral Science, vol. 38, 2006, pp. 72-80.

Performance Management and Delivery Unit (PEMANDU), Economic Transformational Programme Annual Report 2011. Putra Jaya, Malaysia: Prime Minister Department, 2012.

R. K. Sawyer, "Explaining creativity: The science of human innovation,” Oxford $\backslash$ New York: Oxford University Press, 2006.

R. W. Woodman, J. E. Sawyer, and R. W. Griffin, "Toward theory of organizational creativity,” The Academy of Management Journal, vol. 18, 1993, pp. 293-321.

T. M. Amabile, "A model of creavitiy and innovation in organizations," in B. M. Staw and L. L. Cummings (Eds). Research in Organizational Behavior, vol. 10, 1988, pp. 123-167. 


\section{L. TAN, Y. L. HONG}

T. M. Amabile, B. A. Hennessey and B. S. Grossman, "Social influences on creativity: The effects of contracted-for reward," Journal of Personality and Social Psychology, vol. 50, 1986, pp. 14-23.

T. M. Amabile, "Motivating creativity in organizations: on doing what you love and loving what you do,” California Management Review, vol. 41, 1997, pp. 39-58.

T. M. Amabile, "The social psychology of creativity: A componential conceptualization," Journal of Personality and Social Psychology, vol. 45, 1983, pp. 357-376. 